\title{
Custos no setor público
}

Qual é a importância da informação de custos para o aperfeiçoamento das decisões sobre a alocação de recursos e o controle orçamentário - maior qualidade do gasto - no contexto brasileiro?

Qual é a relação entre a contabilidade pública tal como hoje se pratica no setor público brasileiro e a denominada contabilidade de competência (accrual accounting)?

Qual é a diferença entre a contabilidade de competência e o orçamento de competência (accrual budgeting)?

Como relacionar o desenvolvimento de um sistema de informação de custos na administração pública aos esforços mais amplos de reforma da gestão pública: foco em resultados, orientação para os cidadãos, transparência, accountability pública e a identificação de novas formas de prestação dos serviços públicos? Tudo isso no marco da imperiosa necessidade de avançar, anos à frente, no rumo da melhoria da qualidade do gasto público.

Algumas respostas às questões acima constituem o foco deste número da $R A P$. Busca-se contribuir para a reflexão e o debate sobre o que precisa ser feito para a promoção de uma transformação qualitativa na gestão pública, o que, da mesma forma que se observa no cenário internacional, requer o desenvolvimento da capacidade de mensurar e avaliar o desempenho (M\&A) das ações governamentais em todos os níveis da federação brasileira.

O desenvolvimento da M\&A ganha cada vez mais importância na esteira das pressões de contribuintes e cidadãos por apresentação de resultados dos programas e projetos públicos; por eficiência na utilização dos recursos postos à disposição das organizações governamentais; e por cobrar dos políticos e gestores públicos a eficácia e a efetividade desses programas e projetos. Tais pressões crescem à medida que novas tecnologias facilitam o acesso a informações que permitem comparar o desempenho entre diferentes jurisdições e níveis de governo, inclusive numa perspectiva internacional, favorecendo o uso do benchmarking.

Mas como medir e avaliar o desempenho do governo na ausência de informações sistematizadas sobre os custos das ações governamentais em seus 
diferentes níveis de complexidade, isto é, dos programas, projetos e atividades específicas que compõem o âmbito de atuação de cada organização? Essas informações são imprescindíveis para a verificação das relações entre recursos efetivamente utilizados, os "produtos" entregues à sociedade e os benefícios decorrentes dos "produtos". Só assim é possível saber se o resultado está sendo alcançado a um menor custo ou se, com o mesmo volume de recursos, seria possível gerar maiores benefícios para a sociedade.

A importância das informações sobre os custos do governo não se resume à contribuição que elas podem dar para a eficiência e a eficácia do gasto público, mas também pelo que representa à luz da necessidade de ser promovida uma profunda reforma da gestão pública no país, indispensável para que o poder público possa responder adequadamente aos desafios contemporâneos que se apresentam à sociedade brasileira.

O foco em resultados, a ampliação da transparência das ações governamentais, o aumento da accountability de políticos, gestores e profissionais na administração pública, assim como a identificação de novas formas de provisão dos serviços públicos, vistos aqui como críticos elementos para a reinvenção da gestão pública, têm na informação de custos um de seus pilares fundamentais.

A implantação de um sistema de informações de custos afigura-se como estratégia crucial para que o orçamento público e o planejamento governamental se direcionem para as mudanças necessárias. Mais ainda, o aprendizado sobre o que funciona e o que não funciona, obtido mediante a aferição da relação entre custos e resultados, será de fundamental importância para se lidar com o déficit público nos anos à frente, fugindo-se de soluções de "cortes orçamentários" em direção à redefinição de papéis e estratégias, revitalizando a capacidade de governar. Caso, no extremo, seja necessário efetuar "cortes orçamentários", como se observa atualmente em alguns países europeus (Grécia, Espanha e Inglaterra), a disponibilização de informação de custos permite ao gestor público identificar os programas que contribuem com menor value for money e dessa forma utilizar critério técnico para selecionar onde "cortar".

Com a divulgação dos primeiros resultados do trabalho em curso, de implantação de um sistema voltado para a mensuração e avaliação de custos no âmbito do governo federal, cria-se uma valiosa oportunidade para alargar o debate sobre o tema na sociedade brasileira, pela enorme importância de que se reveste.

Fernando Rezende Armando Cunha Ricardo Lopes Cardoso 